\title{
QT Dispersion \& Left Ventricular Hypertrophy in Essential Hypertensive Patients
}

\author{
Gawali SM${ }^{1}$, Shriram $V^{2}$, Jaltade VG $^{3}$ \\ ${ }^{1}$ Dr Sangeeta M Gawali, Associate Professor, Department of Physiology, B J Govt Medical College, Pune, ${ }^{2}$ Miss Veena \\ Shriram, Assistant Professor, Department of Physiology, B. J. Govt. Medical College, Pune, ${ }^{3}$ Dr V G Jaltade, Professor \& \\ Head Department of Physiology, SBH GMC, Dhule, India
}

Address for correspondence: Dr Sangeeta Gawali, Email: sangeetagawali123@yahoo.com

\begin{abstract}
Background: Left ventricular hypertrophy $(\mathrm{LVH})$ is an important indicator of target organ damage in chronic arterial hypertension. An increased risk for life-threatening arrhythmias and sudden death have been observed in hypertensive patients, associated with either left ventricular hypertrophy (LVH) or prolonged QT interval. Present study was conducted to compare QT dispersion in hypertensive patients with LVH \& without LVH. Methods: Forty male subjects affected by essential hypertension with \& without LVH, underwent 12 lead ECG recording for QT dispersion and 2D echocardiography performed to measure interventricular septal thickness, posterior wall thickness and left ventricular internal diameter \& compared with normal age \& sex matched control. Results: There was statistically significant increase in QT dispersion $(\mathrm{p}<0.05)$ in hypertensive subjects with LVH as compared to non-LVH group. Multivariate analysis demonstrated significant relationship between QT dispersion and systolic, diastolic \& mean blood pressure, Left ventricular mass \& Left ventricular mass index. Conclusion: Sympatho-vagal imbalance in hypertensive patients with LVH could contribute to abnormal ventricular repolarization process leading to prolongation of QT dispersion. Manual measurement of QT dispersion might be a simple, non-invasive screening procedure to identify the hypertensive at greatest risk of sudden cardiac death.
\end{abstract}

Key words: systemic essential hypertension, QT dispersion, left ventricular hypertrophy, left ventricular mass index

\section{Introduction}

Hypertension is a complex public health problem. It adversely affects the heart $\&$ blood vessels. It increases the work of the heart \& produces hypertrophy of left ventricle ${ }^{1}$. Left ventricular hypertrophy $(\mathrm{LVH})$ is an important indicator of target organ damage in chronic arterial hypertension ${ }^{2}$. Electrocardiographically and Echocardiographically detected LVH independently predict increased morbidity and mortality including sudden cardiac death $^{3,4}$ and further the relative risk of these events

Manuscript received: $25^{\text {th }}$ June 2013

Reviewed: $13^{\text {th }}$ July 2013

Author Corrected: $29^{\text {th }}$ July 2013

Accepted for Publication: $30^{\text {th }}$ July 2013 increases with increasing left ventricular mass ${ }^{4}$. Experimentally, LVH in hypertension delays ventricular conduction and prolongs action potential duration ${ }^{4}$. Electrocardiographic QRS duration and QT interval measures reflect these changes.Ventricular wall thickness $\&$ inhomogeneity in ventricular repolarization process has been speculated. Increase in QT dispersion is an electrocardiographic measure of ventricular repolarization and also a risk marker for ventricular tachyarrhythmias ${ }^{5}$.

If this hypothesis is correct, measurement of QT dispersion might be a simple, non-invasive screening procedure to identify hypertensive patients who may be at increased risk 
of sudden cardiac death. There is paucity of information on QT dispersion in systemic hypertensive patients with LVH. Therefore, the present study was conducted to evaluate QT dispersion in hypertensive patients \& control group; to find the association between QT dispersion in hypertensive patients with LVH \& without LVH and further to study the association between QT dispersion and various parameters like age, BMI, systolic, diastolic \& mean blood pressure, left ventricular mass (LVM) \& left ventricular mass index (LVMI).

\section{Material \& Methods}

Study population consisted of forty chronic essential hypertensive male patients seen at the cardiology clinic \& medical outpatient department at Sassoon General Hospital, Pune. All subjects of age group between $38 \& 60$ years were evaluated for 12 lead ECG \& compared with those of forty healthy age \& sex matched control (Group I). All hypertensive subjects were categorized into Group IIA (hypertension without LVH, n=20) \& Group IIB (hypertension with LVH, n=20).

Exclusion criteria include diabetes mellitus, stroke, obesity, renal insufficiency, concomitant cardiovascular disease such as rheumatic valvular heart disease, ischemic heart disease or corpulmonale and alcohol consumption, cigarette smoking, history of any drug known to prolong QT interval \& affect LVH

\section{Data collection}

All subjects underwent thorough clinical examination, detailed history \& also they were evaluated for vital parameters like blood pressure, heart rate, BMI. Participants were instructed not to consume tea or caffeine or to engage in strenuous physical activity 12 hours prior to testing. Resting 12 lead ECG was taken in a room with comfortable temperature $\left(22\right.$ to $\left.25^{0} \mathrm{C}\right)$ at the speed of $25 \mathrm{~mm} / \mathrm{sec}$ with gain of $10 \mathrm{~mm} / \mathrm{mV}$.

Uncorrected QT interval, Corrected QT interval (QTc), QT dispersion (QTd) was calculated from 12 lead ECG.

Uncorrected QT interval was calculated as beginning of $\mathrm{Q}$ wave to the end of $\mathrm{T}$ wave i.e. reaching of $\mathrm{T}$ wave to isoelectric line.

Corrected QT interval (QTc) was calculated by Bezett's formula $\mathrm{QTc}=\mathrm{QT} / \sqrt{ } \mathrm{RR}$

QT dispersion (QTd) was calculated as difference between shortest \& longest QT interval recorded from 12 lead ECG. At least three consecutive cycles were measured for each lead and then averaged.

LVH was diagnosed using a 12-lead ECG by following criteria: For example- The $\mathrm{R}$ wave in $\mathrm{V}_{5}$ or $\mathrm{V}_{6}$ plus the $\mathrm{S}$ wave in $\mathrm{V}_{1}$ or $\mathrm{V}_{2}$ exceeds $35 \mathrm{~mm}$.

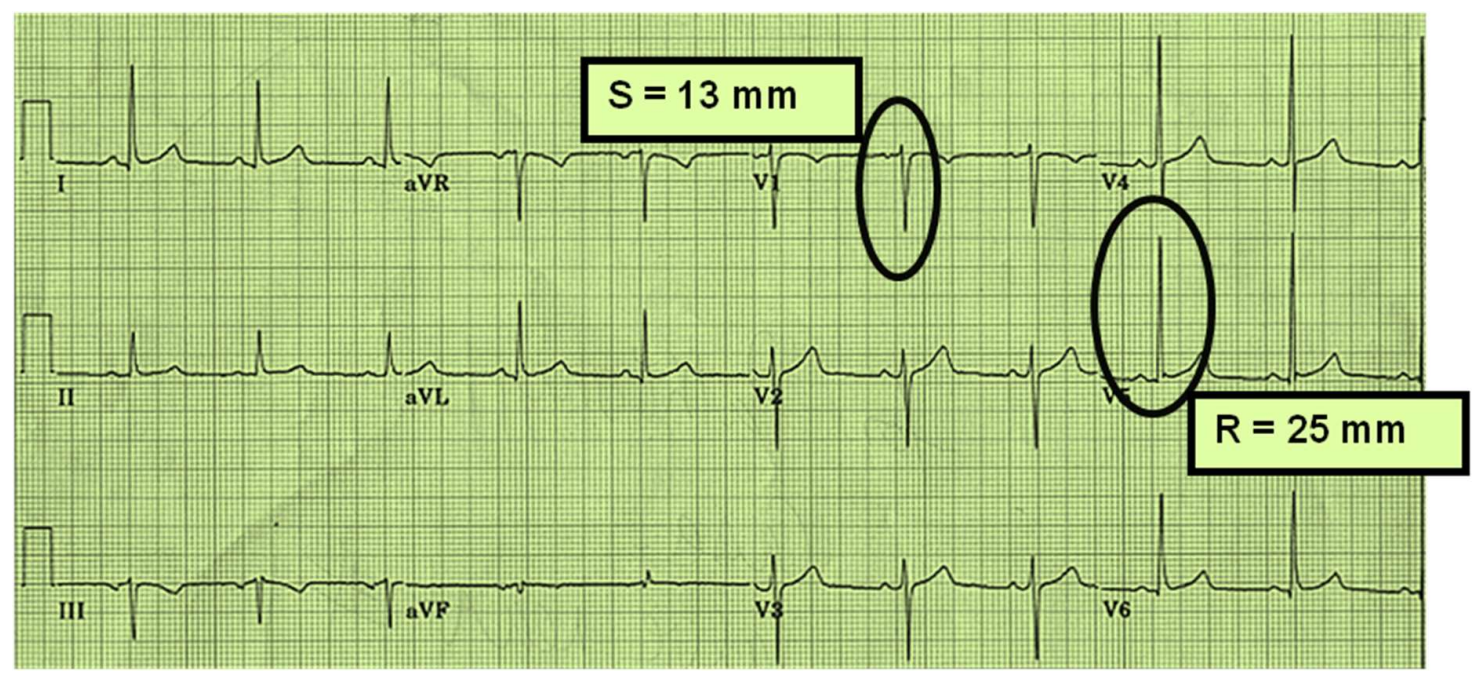

Figure 1: ECG Diagnosis of LVH 
The sensitivity of the ECG in detecting LVH is poor; it tends to underdiagnose. (False negative is more.) Therefore 2D Echo was also performed in CVTS department, Sassoon Hospital to confirm the diagnosis.

2D Echocardiographic examination was performed with Philips iE33 SSD 1700 using a 3.5-MHz transducer. According to the Penn convention ${ }^{7}$, two-dimensional measurements were taken of interventricular septal wall thickness (IVSD), posterior wall thickness (PWT) and left ventricular internal diameter (LVID) at end of diastole in a parasternal long axis view at the level of the mitral valve tips.

Left ventricular mass (LVM) was then calculated according to the formula of Devereux and Reichek 22 and then indexed to body surface area to give left ventricular mass index (LVMI). Left ventricular mass index $>134 \mathrm{~g} / \mathrm{m}^{2}$ was considered significant. Diagnosis of LVH by 2D echo is more sensitive and specific (i.e. True positive is more)

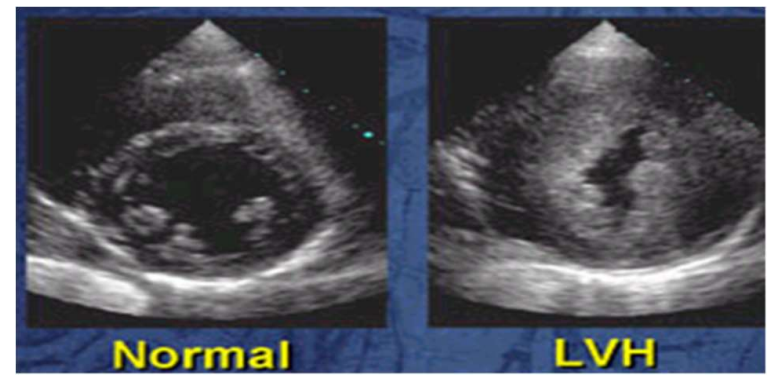

Figure 2: 2D echo of normal and LVH patient

\section{Statistical analysis}

All variables are expressed as mean \pm SD. Unpaired ' $t$ ' test was applied to compare quantitative variables between subjects and control. The level of statistical significance in each case was taken as $\mathrm{P}<0.05$. Pearson's correlation coefficient analysis was performed between QTd \& all variables.

\section{Results}

Table 1: Study Group Characteristics

\begin{tabular}{|c|c|c|c|c|}
\hline Parameters & Group I & Group IIA & Group IIB & P value \\
& (Control) & $\begin{array}{c}\text { (hypertension without } \\
\text { LVH) }\end{array}$ & $\begin{array}{c}\text { Lypertension with } \\
\text { LVH) }\end{array}$ & \\
\hline Sample size & 40 & 20 & 20 & $<9.8+16.1$ \\
\hline Age (years) & $49.5 \pm 15.3$ & $51.7+13.6$ & $26.2+5.81$ & $<0.05$ \\
\hline BMI (Kg/m $\mathbf{m}^{\mathbf{2}}$ & $22.2+4.92$ & $26.9+5.20$ & $179.9+25.2$ & $<0.05$ \\
\hline SBP (mmHg) & $125.6+10.3$ & $170.5+23.2$ & $103.5+23.6$ & $<0.05$ \\
\hline DBP (mmHg) & $79.5+6.0$ & $98.6+21.21$ & $112.9+6.9$ & $<0.05$ \\
\hline MAP(mmHg) & $96.23+4.3$ & $109.3+4.75$ & $307.10+60.0$ & $<0.001$ \\
\hline LVM (g) & $170.10+19.5$ & $259.2+56.2$ & $180.6+70.3$ & $<0.001$ \\
\hline LVMI (g/m $\mathbf{m})$ & $97.3+20.53$ & $155.3+60.12$ & & \\
\hline
\end{tabular}


The age range of the study population was 30-60 years. More than 55\% were in the fifth decade. BMI was more in hypertensive overweight subjects $(\mathrm{p}<0.05)$ than the control group. Systolic, diastolic \& mean blood pressure was significantly higher in hypertensive than control group. $(\mathrm{p}<0.05)$ Left ventricular mass \& left ventricular mass index was higher in group IIB hypertensive $(\mathrm{P}<0.001)$ as compared to group IIA

Table 2: Uncorrected, corrected QT interval and QT dispersion in control and hypertensive group

\begin{tabular}{|c|c|c|c|c|}
\hline Parameters & Group I & $\begin{array}{c}\text { Group IIA } \\
\text { (Control) } \\
\text { (hypertension } \\
\text { without LVH) }\end{array}$ & $\begin{array}{c}\text { Group IIB } \\
\text { (hypertension with } \\
\text { LVH) }\end{array}$ & P Value \\
\hline Uncorrected QT interval (ms) & $283.50 \pm 20.5$ & $362.9 \pm 23.2$ & $402.8 \pm 20.3$ & $(\mathrm{p}<0.05)$ \\
\hline Corrected QT interval (ms) & $305.60 \pm 23.9$ & $396.10 \pm 24.9$ & $440.9 \pm 23.5$ & $(\mathrm{p}<0.05)$ \\
\hline QT dispersion (ms) & $31.9 \pm 9.7$ & $49.2 \pm 9.5$ & $64.0 \pm 23.7$ & $(\mathrm{p}<0.05)$ \\
\hline
\end{tabular}

As per the table Uncorrected QT interval, Corrected QT interval \& QT dispersion was significantly higher in hypertensive than control group $(\mathrm{p}<0.05) \&$ also higher in group IIB as compared to group IIA $(\mathrm{p}<0.05)$

Table 3: Pearson's correlation coefficient between QT dispersion with age, BMI, Systolic, Diastolic \& mean blood pressure, left ventricular mass, left ventricular mass index

\begin{tabular}{|c|c|c|c|}
\hline Parameters & Group IIA & Group IIB & Group I \\
\hline Age (years) & 0.052 & 0.056 & 0.049 \\
\hline BMI $\left(\mathrm{Kg} / \mathrm{m}^{2}\right)$ & 0.083 & 0.098 & 0.067 \\
\hline Systolic BP(mmHg) & $0.179 * *$ & $0.198^{* * *}$ & 0.123 \\
\hline Diastolic BP(mmHg) & $0.193 * *$ & $0.203^{* *}$ & 0.098 \\
\hline Mean BP(mmHg) & $0.198^{* *}$ & $0.211^{* *}$ & 0.102 \\
\hline Left ventricular mass $(\mathrm{gm})$ & $0.169 * *$ & $0.298^{* * *}$ & 0.105 \\
\hline
\end{tabular}

$* \mathrm{P}<0.05 \quad * * \mathrm{P}<0.01 \quad * * * \mathrm{P}<0.001$

This table summarizes the correlation between QT dispersion and other variables. Significant positive correlation existed between QT dispersion and SBP $(p<0.001)$, DBP $(p<0.05)$, MAP $(p<0.05)$, LV mass $(p<0.001)$ and LVMI $(p<0.001)$.

\section{Discussion}

The present study shows following statistically significant findings which need to be addressed

1. Increased QT dispersion in hypertensive patients compared to control group.
2. Comparatively further increase in QT dispersion in hypertensive patients with LVH as compared to Non LVH group.

3. Positive correlation of QT dispersion with systolic \& diastolic blood pressure, Left ventricular mass \& left ventricular mass index.

Available online at: $\underline{\text { www.ijmrr.in }} 79$ | P a g e 


\section{Hypertension \& prolonged QT dispersion}

The main finding of this study is that QT interval is prolonged in hypertensive patients as compared to normotensive. Hypertension is associated with sympathovagal imbalance characterized by vagal withdrawal and relative sympathetic dominance which can trigger ventricular arrhythmias ${ }^{8}$

The QT interval is considered as a marker of ventricular repolarization. The lengthening of QT interval corrected for heart rate (QTc) has been associated with increased risk for either ventricular arrhythmias or sudden cardiac death $^{4,5}$. Prolonged QT interval has been associated with sympathetic predominance or decreased vagal drive ${ }^{8}$.

Sympathetic predominance found in hypertensive patients would indicate a role of autonomic dysfunction in determining abnormal ventricular repolarization, independently that of LVH. Hypertension is therefore associated with prolonged maximum QT interval and increased QT dispersion in a similar way it is associated with the increased risk of left ventricular hypertrophy and clustering of other cardiovascular risk factors. Hypertensive subjects with prolonged QT interval and QT dispersion are therefore at an increased cardiovascular risk compared to others with normal QT intervals 9 .

Some studies have suggested that prolonged QTd is an independent and stronger risk factor for cardiac mortality

in the elderly, stronger than left ventricular hypertrophy and systemic hypertension. ${ }^{10}$

\section{Left ventricular hypertrophy \& prolonged QT Dispersion}

A central role of left ventricular hypertrophy in altering ventricular repolarization has been proposed to explain either QTc lengthening or higher QT dispersion in hypertensive patients ${ }^{11}$, possibly related to structural changes in the hypertrophied myocardium, altering the ion channels operating during the early repolarization phase, and to fibrotic changes in the myocardium leading to electrophysiological heterogeneity ${ }^{12-14}$.

Previous study corroborates similar conclusions by other authors that newly diagnosed hypertensive subjects in developing nations like Nigeria are already more likely to have more target organ damage and excessive cardiovascular morbidity. ${ }^{15}$ The same study also reported that QTd was well correlated with systolic blood pressure and left ventricular mass index among treated hypertensive subjects ${ }^{16}$.

At a microscopic level, LVH is characterized by both myocyte hypertrophy and an increase in collagen interstitial matrix ${ }^{17}$. Myocyte hypertrophy may cause a lengthening of action potential duration, and an increase in interstitial fibrosis may be associated with reduced action potential amplitude and membrane potential, shortened action potential duration ${ }^{18}$. These features could result in an increased QT dispersion if the changes in different parts of the ventricle are nonhomogeneous.

In experimental studies, chronic LVH delays ventricular conduction which seems to be related to an increase in intracellular resistivity caused by increased gap junctional resistance between adjacent cells and to loss of conduction anisotropy. ${ }^{17,18}$

Elevated systemic arterial pressure plays a role in the pathogenesis of left ventricular hypertrophy, the extent of cardiac growth and response to increased pressure loading is not uniform among patients suggesting genetic mechanisms in cardiac hypertrophy ${ }^{5}$.

Antihypertensive therapy has been shown to cause regression of left ventricular hypertrophy, but the effect on left ventricular fibrosis is not well documented. ${ }^{19}$

Early diagnosis \& effective Antihypertensive therapy is the mainstay of preventing cardiovascular morbidity and mortality. 
Echocardiography has been shown to be a very important non-invasive diagnostic tool, but its use in screening all hypertensive for LVH may not be possible, especially in developing countries such as ours, due to cost

Antihypertensive therapy with an angiotensin-converting enzyme inhibitor and calcium antagonist can reduce QT dispersion. This improvement would seem to be mediated by a reduction in LVMI rather than a direct antiarrhythmic effect of the drugs, since QT dispersion did not increase again after drug washout ${ }^{19-20}$.

However, some evidence suggests that angiotensinconverting enzyme inhibitors may be particularly good at reversing changes in the collagen interstitial matrix of the left ventricle ${ }^{20}$. If this fibrosis is the important mediator in the increase in QT dispersion in LVH, simply reducing LV mass by reversing the myocyte hypertrophy is sufficient to reduce QT dispersion.

In the present study, we have found positive correlation between QT dispersion, blood pressure \& LVMI which indicate a more severe form of hypertension, making them more vulnerable to the risk of developing any of the repolarization-related ventricular arrhythmias and therefore sudden cardiac death.

Thus it is recommended that early diagnosis of LVH by $2 \mathrm{D}$ echo \& use of ACE inhibitors \& calcium channel blockers would help to reduce morbidity \& mortality.

\section{Limitations}

One limitation of the present study is the possibility of some subjects having ischemic heart disease, which might influence QT dispersion but no subjects had a suggestive history.

Although all had normal ECGs and no regional wall motion abnormalities on echocardiography, silent ischemia cannot be totally excluded. Second, all of the ECGs were recorded with a standard 12-lead machine. Thus, the leads were not all recorded simultaneously, and this affects both QT dispersion and RR interval measurement. 24 hour ECG monitoring is essential.

\section{Conclusions}

1. QT dispersion is increased in association with an increased LVMI in hypertensive individuals.

2. As an increased QT dispersion is a predictor of sudden death in this group of individuals, then the importance of its reduction is evident.

\section{Acknowledgement}

Authors acknowledge the immense help received from the scholars whose articles are cited \& included in references of this manuscript. The authors are also grateful to authors/editors/publishers of all those articles, journals \& books from where the literature for this article has been reviewed \& discussed.

Authors also wish to thank CVTS Department \& Medicine Department for data collection.

The authors also wish to thank all the volunteers who participated whole heartedly in the study and are grateful to all the staff that have contributed \& cooperated in the study.

Funding: Nil

Conflict of interest: Nil

Permission from IRB: Yes

\section{References}

1. Oikarinen L, Nieminen MS, Viitasalo M, Toivonen L, Sverker J, Dahlo"f B, Devereux RB, Okin PM. QRS Duration and QT Interval Predict Mortality in Hypertensive Patients With Left Ventricular Hypertrophy. Hypertension. 2004;43:1029-1034.

2. Passinoa C, Franzonib F, Gabuttib A, Polettia R, Galettab F, Emdina M. Abnormal ventricular repolarization in hypertensive patients: role of sympathovagal imbalance and left ventricular hypertrophy. International Journal of Cardiology .2004; 97: 57- 623.

Available online at: $\underline{\text { www.ijmrr.in }} \quad 81$ | P a g e


3. Cohen A, Hagan AD, J Watkins J, Mitas J, Schvartzman M, Mazzoleni A, Cohen IM, Warren SE, Vieweg WV. Clinical correlates in hypertensive patients with left ventricular hypertrophy diagnosed with echocardiography. Am J Cardlol 1981;47:335-41

4. Passino C, Magagna A, Conforti F, Buralli S, Kozáková M, Palombo C, Emdin M. Ventricular repolarization is prolonged in nondipper hypertensive patients: role of left ventricular hypertrophy and autonomic dysfunction. J Hypertens 2003; 21(2): 445- 51.

5. Schwartz PJ, Wolf S. QT interval prolongation as predictor of sudden death in patients with myocardial infarction. Circulation 1978;57:1074-7.

6. Pewsner D, Jüni P, Egger M, Battaglia M, Sundstrom J, Bachmann LM. Accuracy of electrocardiography in diagnosis of left ventricular hypertrophy in arterial hypertension: systematic review . BMJ 2007 october 6;355(7622):711

7. Forissier JF, Charron P, Montcel SJD, Hagege A, Isharad R, Carrier L, Richard P, Desnos M, Bouhar JB, Schwartz K, Komajda M, Dubourg O. Diagnostic accuracy of a 2D left ventricle hypertrophy score for familial hypertrophic cardiomyopathy. European Heart Journal. 2005; 26(18): 1882-1886.

8. Grassi G. Role of the sympathetic nervous system in human hypertension. J Hypertens, 1998;16:1979-87.

9. Bexton RS, Vallin HO, Camm AJ. Diurnal variation of the QT interval-influence of the autonomic nervous system. Br Heart J. 1986; 55: 126-30.

10. Shouten EG, Dekker JM, Meppelink P, Kok FJ, Vandenbroucke JP. QT interval prolongation predicts cardiovascular mortality in an apparently healthy population. Circulation. 1991 Oct;84(4):1516- 23.
11. Oikarinen L, Nieminen MS, Viitasalo M, Toivonen L, Wachtell K, Papademetriou V. Relation of QT interval and QT dispersion to echocardiographic left ventricular hypertrophy and geometric pattern in hypertensive patients. The LIFE study. J Hypertens. 2001;19:1883-91.

12. Xiao HB, Brecker SJ, Gibson DG. Relative effects of left ventricular mass and conduction disturbance on activation in patients with pathological left ventricular hypertrophy. Br Heart J. 1994 June;71(6):548- 53.

13. James MA, MacConnell TJ, Jones JV. Is ventricular wall stress rather than left ventricular hypertrophy an important contributory factor to sudden cardiac death? Clin Cardiol. 1995;18:61-5.

14. Kleiman RB, Houser SR. Outward currents in normal and hypertrophied ventricular myocytes. Am J Physiol. 1989;256:1450-61.

15. Cooper R,Rotimi C.Hypertension in blacks. Am J Hypertens.1997;10:804-12

16. Mayet J, Shahi M, McGrath K, Poulter NR,Sever PS,Foale RA, Thome SA. Left ventricular hypertrophy and QT dispersion in hypertension. Hypertension. 1996 Nov;28(5): 791-6.

17. Cooklin M, Wallis WR, Sheridan DJ, Fry CH. Changes in cell-to-cell electrical coupling associated with left ventricular hypertrophy. Circ Res 1997 June; 80(6):765771

18. McIntyre H, Fry $\mathrm{CH}$. Abnormal action potential conduction in isolated human hypertrophied left ventricular myocardium. J Cardiovasc Electrophysiol.1997 Aug;8(8) :887-894.

19. Drayer JIM, Weber MA, Gardin JM, Lipson JL. Effect of long-term antihypertensive therapy on cardiac anatomy in patients with essential hypertension. Am J Med. 1983;78:116-120.

Available online at: $\underline{\text { www.ijmrr.in }} \quad 82$ | P a g e


20. Anversa, E. Puntillo, Niktin P, Olivetti G, Capasso JM.

Cellular and mechanical adaptations in cardiac hypertrophy and its reversal. Cardiovascular Reviews and Reports. 1990; 11: 34-41.

How to cite this article?

Gawali SM, Shriram V, Jaltade VG. QT Dispersion \& Left Ventricular Hypertrophy in Essential Hypertensive Patients. Int J Med Res Rev 2013;1(3):76-83. doi:10.17511/ijmrr.2013.i03.02

Association between Serum Ceruloplasmin level and Dyslipidemia: Study in Tertiary care Teaching Hospital

\section{Dhat $\mathrm{V}^{1}$, Tinaikar $\mathbf{M}^{2}$, Sontakke $\mathrm{A}^{3}$}

${ }^{1}$ Dr Vaishali Dhat, M D, Associate Professor, Department of Biochemistry, ${ }^{2}$ Miss Madhura Tinaikar

International Journal of Medical Research and Review Available online at: $\underline{\text { ww.ijmrr.in }} 83$ | P a g e

